\title{
Design of GPON network based on FTTH
}

\author{
Qiang Han ${ }^{1,}$, Xingxing Huan ${ }^{2, b}$
}

${ }^{1}$ Satellite Maritime Tracking and Control Department, Jiangsu Jiangyin 214431,China;

${ }^{2}$ Satellite Maritime Tracking and Control Department, Jiangsu Jiangyin 214431, China.

a1510603630@qq.com, b1430184616@qq.com

Keywords: FTTH, Triple play, GPON.

\begin{abstract}
With the continuous improvement of living standards, the development of broadband network technology. Telephone, TV, network Trinity service way more and more popular. FTTH latest generation GPON passive optical network, to meet the needs of high efficiency broadband utilization, large area coverage, client interface convenient.
\end{abstract}

\section{FTTH network profile}

FTTH network using GPON technology to set up a home access network, telephone, television and Internet services by users of FTTH access network, realize the integration of three networks, including: light splitter, optical fiber and optical cable distributing box and a series of optical passive devices. FTTH is based on the ONU and the user's distance to judge, ONT directly installed in the cabin, the fiber directly into the cabin, so FTTH also known as the fiber to the home or fiber to the home.

GPON supports up 1.25Gbit/s, downlink 2.5Gbit/s access rate, the maximum physical distance support $20 \mathrm{~km}$, the maximum logical distance $60 \mathrm{~km}$ long transmission distance. At the same time support the 1:64 of the split ratio, the expansion can support the 1:128 split ratio, with a large number of coverage of the user, such as the advantages of large coverage. Support: voice, data, video. GPON supports high bandwidth transmission, which can effectively solve the bandwidth bottleneck of twisted pair access, and meet the needs of users for high bandwidth services, such as high definition $\mathrm{TV}$, live broadcast and so on. GPON supports long distance access, which can solve the problem of long distance coverage, and reduce the network nodes.

\section{Major equipment and functions}

\subsection{OLT}

GPON is a high bandwidth, full service system, a PON port can be hung up 128 sets of ONT equipment. OLT is GPON passive optical network system equipment at office end, is a multi service provide a platform to support IP service and the traditional TDM services at the same time, ascending to each ONU bandwidth allocation in accordance with the time division multiplexing, downward to the ONU through broadcasts Ethernet according to. To initiate and control the ranging process, and to record the distance information. Allocate bandwidth for ONU, which controls the start time of the ONU and the size of the sending window.

\section{$2.2 \mathrm{ONU}$}

ONU optical network nodes are divided into active optical network unit and passive optical network unit. The optical node includes optical pick up and monitoring equipment, its main function: broadcast Ethernet data receiving OLT sent. In response to the distance and power control commands issued by the OLT, while the corresponding adjustment. Will be the user's Ethernet data cache, and in the OLT distribution of the transmission window to send the uplink direction.

\subsection{ODN}

ONU optical distribution network, composed of fiber, a or a plurality of passive optical splitter is passive optical devices, optical channel between the OLT and ONU, plays a role in linking the OLT and ONU, with very high reliability. 


\section{Networking mode}

FTTH is refers to the optical network unit installed to the user. FTTH not only provides greater network bandwidth, but also enhances the communication network to the data format, speed and wavelength, and the transparency of the protocol, simplify the power supply requirements, simplify the maintenance and installation. At present, in the application of FTTH engineering technology, the main mode is OLT through the optical splitter directly connected to the ONU. ONU single dwelling units OLT uplink, the second line of a couplet is connected through an Ethernet interface, is connected with telephone, computer, TV, achieve the "triple play" service access.

GPON network using fiber OLT, splitter and ONU connected on the downlink using different wavelength data bearing. Uplink using 1310nm wavelength, downlink using 1490nm wavelength. GPON system using the principle of wavelength division multiplexing (WDM) through different uplink and downlink wavelengths in the same ODN network for data transmission, downward send data through the radio, while the upstream through TDMA mode, according to the time slot were upload data.

According to the user distribution reasonable settings of the region, sub region is a to concentrated spot as the center covering area, spot setting on the client access to the engine room. Light splitter installation focuses on security and user installation operability.

\section{Network design}

\subsection{Needs analysis}

To office life a total of 5 layers, for example, 3-4 layer for the centralized office, 1 network centers; 3-5 layer is expected to be 200 users. The specific needs of the network: to achieve a comprehensive business access, to meet the same number of simultaneous use of telephone, Internet and television business. Network large capacity access, the need for $100 \mathrm{Mb} / \mathrm{s}$ network access, and multi user IPTV multicast service. Considering the cost of network construction. Providing secure and reliable access network.

\subsection{Access to the total bandwidth design}

According to the telephone, Internet, IPTV business is through different ports access service network, in accordance with the requirements of the business users, broadband optical network 4M/ households above, IPTV business 3m / households, household telephone 128K/, computing FTTH access total bandwidth demand about $800 \mathrm{~m}$.

\subsection{OLT design}

OLT design principles of high bandwidth, large capacity voice, data and IPTV and other integrated services access. Huawei MA5683T equipment, GPON access capability can be single fiber to provide voice, data and the IPTV service; uses point to multipoint structure, passive optical network transmission mode, supporting uplink $1.25 \mathrm{gbit} / \mathrm{s}$ rate, rate of the downlink $2.5 \mathrm{gbit} / \mathrm{s}$; to support broadband dynamic allocation DBA algorithm; using passive optical transmission technology, optical path are separated by p2mp (point to multiple point) to support 1:64 optical divide ratio.

\subsection{Service access requirements design}

The telephone, television and Internet service access the FTTH network, the ONU device China interface panel has a fiber optic interface, the fiber connection of the interface, through the optical splitter and OLT connection, realize the OLT and ONU connection. The interface panel is designed with an adaptive Ethernet interface, and the computer is connected to the RJ-45 interface to realize the broadband Internet access, and the TV set is connected with the RJ-45 interface through the set-top box to realize the IPTV service access. Another interface panel is designed to VoIP phone interface, telephone and RJ-11 connection to complete the voice service access.

\subsection{Passive optical distribution network design}

ODN is in the FTTH network between OLT and ONU physical network cable, ODN network by the OLT uplink cable, divided into light device and a branch line cable is composed of three parts. 
Therefore, in FTTH network ODN throughout the optic backbone layer, a wiring layer, users are introduced into the layer. ODN design scheme mainly according to the user needs to design the optical cable selection and optical splitter settings. In the way of setting up the ODN network, the project adopts 1:16 to divide the light, which makes the scoring optical network to be more excellent, the fault point is less, and it is convenient for troubleshooting.

\section{Performance test}

An OLT is connected with a plurality of ONU through the optical splitter, and the ONU Ethernet interface is connected with the network analyzer SmartBits600, and the OLT Ethernet interface is connected with the same network analyzer to form a closed loop circuit. Network analyzer is responsible for sending Ethernet packets to ONU, after the uplink to reach OLT, and then return to the analyzer. Based on SmartBits600, multicast packets with different frame length are constructed separately from the aggregation switch and the ONU side. The test service is the packet loss rate, the bit error rate, and the time delay.

Table 1 OLT-ONU

\begin{tabular}{|c|c|c|c|c|c|}
\hline $\begin{array}{c}\text { Test frame length } \\
\text { (byte) }\end{array}$ & $\begin{array}{c}\text { bandwi } \\
\text { dth }\end{array}$ & $\begin{array}{c}\text { Uplink packet } \\
\text { loss rate }\end{array}$ & $\begin{array}{c}\text { Downlink packet } \\
\text { loss rate }\end{array}$ & error rate & $\begin{array}{c}\text { Time delay } \\
\text { (us) }\end{array}$ \\
\hline 64 & 100 & 0 & 0 & 0 & 32.0 \\
\hline 128 & 100 & 0 & 0 & 0 & 37.8 \\
\hline 256 & 100 & 0 & 0 & 0 & 48.9 \\
\hline 512 & 100 & 0 & 0 & 0 & 71.6 \\
\hline 1024 & 100 & 0 & 0 & 0 & 117.4 \\
\hline 1280 & 100 & 0 & 0 & 0 & 141.3 \\
\hline 1518 & 100 & 0 & 0 & 0 & 165.3 \\
\hline
\end{tabular}

Table 2 ONU-ONU

\begin{tabular}{|c|c|c|c|c|c|}
\hline $\begin{array}{c}\text { Test frame length } \\
\text { (byte) }\end{array}$ & $\begin{array}{c}\text { bandwi } \\
\text { dth }\end{array}$ & $\begin{array}{c}\text { Uplink packet } \\
\text { loss rate }\end{array}$ & $\begin{array}{c}\text { Downlink packet } \\
\text { loss rate }\end{array}$ & error rate & $\begin{array}{c}\text { Time delay } \\
\text { (us) }\end{array}$ \\
\hline 64 & 100 & 0 & 0 & 0 & 168.0 \\
\hline 128 & 100 & 0 & 0 & 0 & 178.8 \\
\hline 256 & 100 & 0 & 0 & 0 & 197.4 \\
\hline 512 & 100 & 0 & 0 & 0 & 242.0 \\
\hline 1024 & 100 & 0 & 0 & 0 & 352.6 \\
\hline 1280 & 100 & 0 & 0 & 0 & 383.8 \\
\hline 1518 & 100 & 0 & 0 & 0 & 322.5 \\
\hline
\end{tabular}

After testing, fully shows the good running ability of the project. GPON system performance indicators are normal, the device is running well.

\section{Concluding remarks}

In this paper, we first design the triple play project based on the architecture GPON bearer network, and complete the voice, video, telephone fiber to the user. Project construction and installation according to the needs of users to adjust the business interface access, construction is convenient, easy to operate. For the next step of the network construction to provide their own ideas, there are 
many in the implementation of the not in place, in the future need to continue to improve the specific practice.

\section{Reference}

[1] FTTH network design and practice of triple play Hunan University He Yuechun

[2] Mcgarry M, Reisslein M, et al. Ethernet passive optical network architectures and dynamic bandwidth allocation algorithms. IEEE Communications Surveys, 2008, 10(3):46-60

[3] Skubic B, Chen JJ, Ahmed J, Wosinska L, et al. A comparison of dynamic bandwidth allocation for EPON, GPON, and next-generation TDM PON. IEEE Communications Magazine, 2009, 47(3):S40-S48

[4] Hajduczenia M, da Silva H, Borges N. Discovery process for emerging $10 \mathrm{~Gb} / \mathrm{s}$ EPONs. IEEE Communications Magazine, 2008, 46(11): 82-90

[5] Choi SY Lee S, Lee TJ, Chung MY, et al. Double-Phase polling algorithm based on partitioned ONU subgroups for high utilization in EPONs. Journal of Optical Communication Network, 2009, 1(5):484-497

[6] Zhang JY, Liu L. Implement mechanism on distributed EPON DBA based on utility. Journal of Software, 2008, 19(7):1693-1706

[7] Lim W, Yun $\mathrm{CH}$, et al. Burst-Polling-Based dynamic bandwidth allocation using adaptive minimum guaranteed bandwidth for EPONs. Journal of Optical Communication Network, 2009, 1(7):594-599

[8] Sue CC, Cheng HW. A fitting report position scheme for the gated IPACT dynamic bandwidth algorithm in EPONs. IEEE/ACM Trans. on Networking, 2010, 18(2):624-637

[9] Ikeda H, Kitayama K. Dynamic bandwidth allocation with adaptive polling cycle for maximized TCP throughput in 10G-EPON. Journal of Lightwave Technology, 2009, 27(23):5508-5516

[10] Meng L, El-Najjar J, Alazemi H, et al. A joint transmission grant scheduling and wavelength assignment in multichannel SG-EPON. Journal of Lightwave Technology, 2009, 27(21):4781-4792

[11] Xu H, Datta A, Bhattacharyya SP. PID stabilization of LTI plants with time-delay. In: Proc. of the 42nd IEEE Conf. on Decision and Control. 2003, 4:4038-4043

[12] Jiang S M, Xie J. A frame division method for prioritized DBA in EPON. IEEE Journal on Selected Areas in Communications, 2006, 24(4):83-94

[13] Shumate P W. Fiber-to-the-Home: 1977-2007. Journal of Lightwave Technology, 2008, 26(9):1093-1103 